\title{
Assessment of the relationship between neutrophil lymphocyte ratio and prognostic factors in non-metastatic colorectal cancer
}

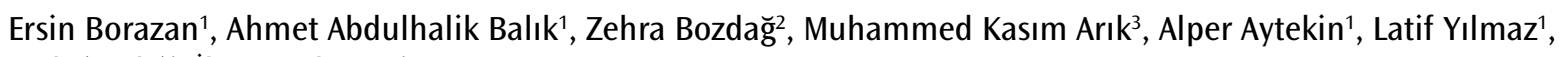
Muhsin Elçi', Illyas Bașkonuş ${ }^{1}$

\section{ABSTRACT}

Cite this paper as: Borazan E, Balık AA, Bozdağ Z, Arık MK, Aytekin A, Y.Imaz L, Elçi M, Başkonuş I. Assessment of the relationship between neutrophil lymphocyte ratio and prognostic factors in non-metastatic colorectal cancer. Turk J Surg 2017; 33: 185-189.

'Department of General Surgery, Gaziantep University School of Medicine, Gaziantep, Turkey 2Department of Pathology, Gaziantep University School of Medicine, Gaziantep, Turkey ${ }^{3}$ Department of General Surgery, Çanakkale Onsekiz Mart University School of Medicine, Gaziantep, Turkey

Address for Correspondence Ersin Borazan

e-mail: ersinborazan@hotmail.com

Received: 14.02.2016

Accepted: 13.06 .2016

CCopyright 2017

by Turkish Surgical Association

Available online at

www.turkjsurg.com
Objective: Neutrophil-lymphocyte ratio still has a limited clinical use due to many non-cancer factors affecting neutrophils or lymphocytes in the present time. We aimed to evaluate the association between preoperative neutrophillymphocyte ratio and poor prognostic factors after curative elective colorectal surgery.

Material and Methods: This clinical retrospective study was initiated with 95 patients, who had a curative surgical resection between 2003 and 2013. The patients were divided into two groups based on the preoperative neutrophillymphocyte ratio cut-off value above and below 3 . The groups were compared for tumor localization, diameter, and staging; the histopathological perineural invasion; lymphovascular invasion; and overall survival. Univariate and multivariate Cox regression analyses were used to determine the role of neutrophil-lymphocyte ratio after stratification by several clinicopathological factors.

Results: The mean age of patients was $59.79 \pm 1.48$ (range, 23-90) years, and median follow-up period was $20.77 \pm 14.85$ months. There was no significant difference in perineural or lymphovascular invasion, tumor size, stage, age, sex, and tumor location between the groups [Group 1 ratio $>3(n=52)$ and Group 2 ratio $\leq 3(n=43)$ ]. Hemoglobin ( $p=0.035)$ and albumin levels $(p=0.004)$ were lower in the Group 1 . When the stage increased, differences between the rectal cancer groups were found. Overall survival was significantly lower in the Group 1 ( $p=0.013$ ).

Conclusions: The study showed that a high neutrophil-lymphocyte ratio had an adverse effect on overall survival in colorectal cancer patients who had a curative surgery. However, we could not establish any association between neutrophil-lymphocyte ratio and the factors such lymphovascular invasion, perineural invasion, tumor size expect hemoglobin and serum albumin levels.

Keywords: Colorectal cancer, lymphocyte, neutrophil, surgery, overall survival

\section{INTRODUCTION}

Colorectal cancer is the third most common malignancy worldwide. The number of deaths from colorectal cancer is 15.9 per 100,000 individuals per year. Approximately $4.7 \%$ of men and women are diagnosed with colon and rectal cancer at some point during their lifetime (1). Estimated preoperative prognosis for colorectal cancer patients will help the choice and modality of the surgical and medical treatment.

An improved lifespan has been shown with an intensive lymphocytic infiltration in localized tumors in the colorectal cancer patients (2-4). Additionally, some parameters, such as C-reactive protein and hypoalbuminemia, which show a poor prognostic association between systemic inflammatory response and colorectal cancer have been discussed $(5,6)$. Systemic inflammation has been reported to be an independent determining factor for prognosis in colorectal patients after surgery (5). A high neutrophillymphocyte ratio (NLR) has been reported to estimate poor outcomes in colorectal cancer patients who are exposed to primary resection (7). Ding (8) reported that a high NLR may establish the risk groups and in such patients NLR may be a marker in response at adjuvant cancer therapy.

Considering the histopathology of colorectal diseases, it is known that lymphovascular and perineural invasion have an adverse effect on prognosis. The most important prognostic variable in colorectal carcinoma is the presence or absence of lymph node metastases. In a study of more than 1000 operative specimens, Morson and Dawson (9) found regional venous involvement in 35\% of cases. Submucosal venous spread occurred in $10 \%$ of cases, and there was an evidence of permeation of extramural vessels in $25 \%$ cases. In the former cases, there was little or no effect on prognosis; however, extramural venous involvement reduced five-year survival rates from $55 \%$ to approximately $30 \%$.

Perineural invasion (PNI) has been shown to have a detrimental effect on the prognosis (10). Its presence may be a part of overall penetration of the bowel wall. The relationship between PNI and the advanced colorectal cancer patients was reported in 1981 (11). Krasna et al. (12) found that the three-year survival rate decreased from $57.7 \%$ in patients without neural invasion to $29.6 \%$ in patients with neural invasion. 
Of 128 operative specimens examined by Horn, Dahl, and Morild (13), neural invasion was demonstrated in $32 \%$. The fiveyear survival rate in patients with neural invasion was $64.3 \%$ compared with $81.1 \%$ when neural invasion was not demonstrated. A grading system was established based on the "intensity" (number of the perineural invasion foci in a 20-power field) and "depth" (distance from the muscularis propria). The PNI grading system may be useful in prognosis, and may allow case selection for intensive postoperative adjuvant therapy.

The present study has aimed to evaluate the association between NLR levels and prognostic factors in colorectal cancer patients who have a curative elective surgical resection.

\section{MATERIAL AND METHODS}

The present study retrospectively evaluated the files and the electronic data of patients who were surgically treated with the diagnosis of a colorectal cancer between January 2003 and December 2013 in the Gaziantep University Hospital. The study was approved by the Gaziantep University Local Ethics Committee with the decision no: 20.01.2014/48.

The patients for whom file data could not be completely accessed, who could not be followed up, who did not have detailed pathological examinations, who underwent an urgent surgery (due to perforation or obstruction), who had preoperative infections, who had a history of hematological disease or chronic inflammatory diseases, who received preoperative chemotherapy, and who had distant metastases were excluded.

Based on these criteria, among 268 patients who underwent colorectal cancer surgery, we included 95 patients who were diagnosed with adenocarcinoma and had only a curative surgery.

Patients' age, gender, tumor localization, tumor diameter, tumor classification, staging, presence or absence of a histopathological perineural, and lymphovascular invasion were recorded. The evaluation of vascular invasion was based on whether there was extramural involvement. Any pathological grading system was not used for the determination of perineural invasion. The lifetime data of the patients were collected using the hospital and the national databases.

From laboratory tests studied within last one week before surgery, the levels of neutrophils, lymphocytes, hemoglobin, and albumin were recorded. NLR was calculated. The values with the highest sensitivity and specificity were analyzed for NLR cut-off value based on cut-off values established according to the ROC curve analyses in some previous studies with a large number of patients $(14,15)$. The patients were divided into two groups based on an NLR cut-off value of three. Clinical-pathological characteristics and overall survival (OS) were compared between two groups.

\section{Statistical Analysis}

Descriptive analyses were conducted for the demographic parameters. Clinical-pathological characteristics between the groups were analyzed using Mann-Whitney $U$ test and chisquare test, which are non-parametric tests. The survival was multivariate survival analyses were made for the association between NLR and clinical and pathological parameters in OS. The Statistical Package for the Social Sciences 22.0 for system (IBM Corp.; Armonk, NY, USA) was used as statistical program.

\section{RESULTS}

The clinical and the pathological characteristics of the 95 patients who had a curative resection with the diagnosis of the colorectal cancer were studied. The mean age was $59.79 \pm 1.48$ (range: $23-90$ ) years. The female/male ratio was $40 / 55$ (57.9\%/42.1\%). The median follow-up duration was $20.77 \pm 14.85$ months. The tumor localization was in the colon $(54.74 \%)$ and in the rectum (45.26\%). The most common localization in the colon cancer form was the sigmoid colon and the right colon (Table 1).

The groups were based on NLR $>3(n=52)$ and NLR $\leq 3(n=43)$. Table 2 compares the clinicopathological characteristics between the groups. There was no difference in the age and sex distribution between the groups. There was a difference between the groups according to the localization of the colon and rectum, but it was not statistically significant $(p=0.060)$. The proportion of colon/rectum patients was 33/19 in Group 1 and 19/24 in Group 2. Therefore, the colon and rectum cases were evaluated separately according to the stage. There were differences in stage 2 colon cancer between the colon groups. However, this situation did not reflect in stage 3 colon cancer. There were differences between the groups with regard to the stage 2 and 3 rectal cancer. This situation suggested that a high NLR is important in intermediate stage rectal cancer.

No significant difference was noted between NLR level and perineural or lymphovascular invasion. Lower hemoglobin and albumin levels in the high-NLR group were the only differences.

Table 1. Clinical and pathological features of patients

Number of patients (percent)

\begin{tabular}{|lc|}
\hline Sex ratio (Female:Male) & $40: 55(47 \%-53 \%)$ \\
\hline Age (years) & $59.79 \pm 1.48(23-90)$ \\
\hline Site of colorectal cancer & $\mathrm{n}(\%)$ \\
$\quad$ Right colon & $16(16.84)$ \\
Transvers colon & $5(5.26)$ \\
Left colon & $6(6.31)$ \\
Sigmoid colon & $25(26.31)$ \\
\hline Rectum & $43(45.26)$ \\
\hline Stage & $\mathrm{n}(\%)$ \\
\hline Stage 1 & $15(15.78)$ \\
\hline Stage 2 & $35(36.84)$ \\
\hline Stage 3 & $45(47.36)$ \\
\hline Tumor size (cm) & $5.13 \pm 2.04(1.20-13.00)$ \\
\hline Follow up (month) [mean, SD, & $20.77 \pm 14.85(1-82)$ \\
(min-max)] & $12.19 \pm 1.94(6.7-16.30)$ \\
\hline Hemoglobin & $3.86 \pm 0.55(2.16-4.90)$ \\
\hline Albumin &
\end{tabular}


Table 2. The features of patients with high and low NLRs

\begin{tabular}{|c|c|c|c|c|}
\hline & & $\begin{array}{l}\text { NLR }>3 \\
(n: 52)\end{array}$ & $\begin{array}{l}\mathrm{NLR} \leq 3 \\
(\mathrm{n}: 43)\end{array}$ & $p$ \\
\hline Age & & $\begin{array}{c}62.13 \pm 14.81 \\
(23-90)\end{array}$ & $\begin{array}{c}56.95 \pm 13.66 \\
(28-79)\end{array}$ & 0.063 \\
\hline Sex (Female/Male) & & $18 / 34$ & $22 / 21$ & 0.156 \\
\hline \multirow[t]{2}{*}{ Locations } & Colon & $33(63.46 \%)$ & $19(44.19 \%)$ & \multirow[t]{2}{*}{0.130} \\
\hline & Rectum & $19(36.54 \%)$ & 24 (55.81\%) & \\
\hline Tumor size & & $\begin{array}{l}5.13 \pm 2.12 \\
\quad(2-11)\end{array}$ & $\begin{array}{c}5.10 \pm 1.95 \\
(1.2-13)\end{array}$ & 0.795 \\
\hline \multirow[t]{3}{*}{ Colon Stage } & 1 & $4 / 33$ & $1 / 19$ & 0.200 \\
\hline & 2 & $14 / 33$ & $9 / 19$ & $0.033^{*}$ \\
\hline & 3 & $15 / 33$ & $9 / 19$ & 0.087 \\
\hline \multirow[t]{3}{*}{ Rectum Stage } & 1 & $2 / 19$ & $8 / 24$ & 0.164 \\
\hline & 2 & $5 / 19$ & $7 / 24$ & $0.002^{*}$ \\
\hline & 3 & $12 / 19$ & $9 / 24$ & $0.003^{*}$ \\
\hline \multirow[t]{4}{*}{$\mathrm{T}$} & 1 & $385.76 \%)$ & $2(4.65 \%)$ & \multirow[t]{4}{*}{0.636} \\
\hline & 2 & $7(13.46 \%)$ & $9(20.93 \%)$ & \\
\hline & 3 & 32 (61.53\%) & 27 (62.79\%) & \\
\hline & 4 & $10(19.23 \%)$ & $5(11.62 \%)$ & \\
\hline \multirow[t]{3}{*}{$\mathrm{N}$} & 0 & 25 (4.07\%) & $25(58.13 \%)$ & \multirow[t]{3}{*}{0.616} \\
\hline & 1 & $14(26.92 \%)$ & $9(20.93 \%)$ & \\
\hline & 2 & $13(25.00 \%)$ & $9(20.93 \%)$ & \\
\hline \multirow{2}{*}{$\begin{array}{l}\text { Perineural } \\
\text { invasion }\end{array}$} & Negative & $36(69.23 \%)$ & 32 (74.41\%) & \multirow[t]{2}{*}{0.742} \\
\hline & Positive & $16(30.76 \%)$ & 11 (25.58\%) & \\
\hline \multirow{2}{*}{$\begin{array}{l}\text { Lymphovascular } \\
\text { invasion }\end{array}$} & Negative & 32 (61.53\%) & 25 (58.13\%) & \multirow[t]{2}{*}{0.899} \\
\hline & Positive & 20 (38.46\%) & $18(41.86 \%)$ & \\
\hline Hemoglobin & & $\begin{array}{c}11.84 \pm 1.82 \\
(8.4-15.6)\end{array}$ & $\begin{array}{c}12.63 \pm 2.03 \\
(6.7-16.3)\end{array}$ & $0.035^{*}$ \\
\hline Albumin & & $\begin{array}{l}3.70 \pm 0.58 \\
(2.16-4.67)\end{array}$ & $\begin{array}{c}4.04 \pm 0.48 \\
(2.8-4.9)\end{array}$ & $0.004^{*}$ \\
\hline
\end{tabular}

NLR: neutrophil-lymphocyte ratio; T: tumour size staging; N: lymph node metastasis staging

${ }^{*} p<0.05$

For all patients, the two-year and the five-year OS were $75.6 \%$ and $66.0 \%$, respectively. As of August 2014, 18 and six patients died in high-NLR and low-NLR groups, respectively. Figure 1 presents the OS graph of the groups. High NLR was related with significantly poor OS outcomes (Log-rank test, $p=0.013$ ).

To investigate whether NLR was associated with clinical and pathological outcomes, univariate and multivariate survival analyses for OS was performed.

Univariate analysis revealed high NLR as a poor prognostic indicator of OS outcomes of patients, whereas age, gender, pathological $\mathrm{T}$ and $\mathrm{N}$ stages, tumor size, lymphovascular invasion, and perineural invasion were not significantly associated with OS.

A similar result was noted with multivariate analysis as well. High NLR was identified as an independent prognostic factor

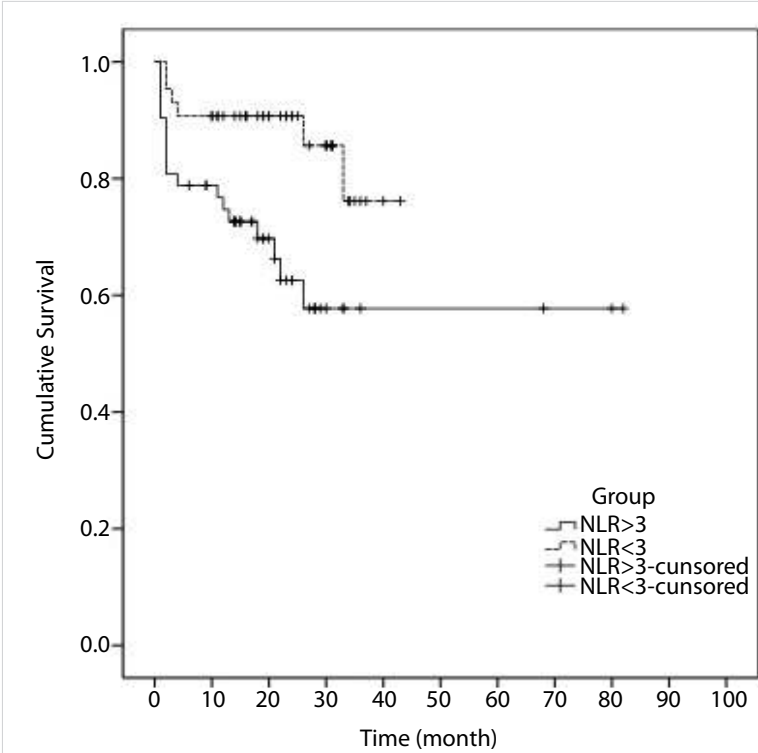

Figure 1. Kaplan-Meier curves for OS of the patients with colorectal cancer based on the NLR groups

for OS [hazards ratio $(\mathrm{HR})=3.003 ; 95 \% \mathrm{Cl}=1.189-7.589 ; \mathrm{p}=0.02$ ] as outlined in Table 3.

\section{DISCUSSION}

Colorectal cancers have an important role in deaths from cancer worldwide. Local recurrence and distant metastases may occur in the advanced periods even in patients who have undergone curative resection. High preoperative NLR is associated with poor prognostic factors in colorectal cancer (16).

The study by Roxburgh suggested that low peritumoral infiltration and increased systemic inflammation were linked via the cell-mediated immune system. Both the pathologic and the biochemical measures of the inflammatory response predicted the survival after colorectal cancer surgery (17). In a study of 374 patients (229 with negative node disease) who underwent a surgery between 1986 and 1996, the systemic inflammatory response measured by Glasgow prognostic score (mGPS) criteria was neither associated with Dukes stage nor with peritumoral infiltration, but was associated with an increased number of circulating total white blood cells and neutrophils and a decreased number of circulating lymphocytes. mGPS was also independently associated with cancer-specific survival in patients potentially undergoing a curative resection for colorectal cancer (18).

This present study evaluated several clinical and pathological characteristics including perineural and lymphovascular invasion, but could not establish a significant correlation between NLR and such parameters. Only hemoglobin and albumin levels were significantly lower in the high NLR group.

This study showed that high NLR significantly affected OS. However, no significant correlation was established between NLR and perineural and lymphovascular invasion, which are known to be poor prognostic factors. It may also be affected by the exclusion of the stage 4 patients, receiving neoadjuvant chemoradiotherapy based on evaluation of the association between NLR and perineural-lymphovascular invasion. This is 
Table 3. Univariate and multivariate analyses of clinicopathological parameters for the prediction of OS in the patients with colorectal cancer

\begin{tabular}{|c|c|c|c|c|c|}
\hline & & \multicolumn{2}{|c|}{ Univariate analysis } & \multicolumn{2}{|c|}{ Multivariate analysis } \\
\hline & & $\mathrm{HR}(95.0 \% \mathrm{Cl})$ & $\mathrm{p}$ & HR $(95.0 \% \mathrm{Cl})$ & $p$ \\
\hline \multicolumn{2}{|l|}{ Age } & $1.028(0.995-1.062)$ & 0.099 & $1.030(0.993-1.069)$ & 0.118 \\
\hline Sex & (male vs female) & $1.867(0.774-4.506)$ & 0.165 & $1.376(0.488-3.883)$ & 0.547 \\
\hline \multicolumn{2}{|l|}{ Tumor size } & $1.149(0.965-1.367)$ & 0.119 & $1.198(0.970-1.480)$ & 0.093 \\
\hline \multirow[t]{4}{*}{$\mathrm{T}$} & $\mathrm{T} 1$ & 1 & 0.351 & 1 & \\
\hline & T2 (2 vs 1$)$ & $0.289(0.018-4.646)$ & 0.381 & $0.197(0.011-3.597)$ & 0.273 \\
\hline & T3 (3 vs 1) & $1.737(0.231-13.058)$ & 0.592 & $0.772(0.082-7.284)$ & 0.821 \\
\hline & T4 (4 vs 1) & $1.727(0.192-15.551)$ & 0.626 & $0.663(0.061-7.243)$ & 0.736 \\
\hline \multirow[t]{3}{*}{$\mathrm{N}$} & No & 1 & 0.246 & 1 & \\
\hline & N1 (1 vs 0) & $1.614(0.600-4.339)$ & 0.343 & $0.994(0.192-5.136)$ & 0.994 \\
\hline & N2 (2 vs 0 ) & $2.242(0.864-5.817)$ & 0.097 & $1.301(0.189-8.977)$ & 0.789 \\
\hline PN invasion & Positive vs negative & $1.771(0.786-3.988)$ & 0.168 & $1.376(0.483-3.920)$ & 0.550 \\
\hline LV invasion & Positive vs negative & $2.133(0.947-4.805)$ & 0.068 & $1.747(0.306-9.982)$ & 0.531 \\
\hline \multicolumn{2}{|l|}{ Hemoglobin } & $1.007(0.819-1.237)$ & 0.947 & $1.042(0.792-1.371)$ & 0.770 \\
\hline \multicolumn{2}{|l|}{ Albumin } & $0.630(0.322-1.231)$ & 0.177 & $0.958(0.390-2.352)$ & 0.926 \\
\hline Groups & $(N L R>3$ vs $N L R \leq 3)$ & $3.003(1.189-7.589)$ & $0.020^{*}$ & $3.055(1.080-8.638)$ & $0.035^{*}$ \\
\hline \multicolumn{6}{|c|}{$\begin{array}{l}\text { OS: overall survival; PN: perineural invasion; LV: lymphovascular; T: tumour size staging; } \mathrm{N} \text { : lymph node metastasis staging; HR: hazard ratio; Cl: confidence } \\
\text { interval } \\
\text { *p<0.05 }\end{array}$} \\
\hline
\end{tabular}

due to the fact that such invasions are more frequent in advanced stage patients.

Ozdemir et al. (19) in their study, found by the univariate analysis that there is a correlation between high NLR and pathologic nodal stage of bad OS. However, in our study, there was no statistical correlation established by univariate and multivariate analysis between groups in terms of lymphovascular invasion and TNM stage. A reason of this difference may be the exclusion of study of metastatic patients.

Intratumoral immun T cell densities on the colon or the rectum are especially associated with tumor enlargement and metastasis (20). There is a significant difference in the advanced rectum cancer groups. As in many studies, we did not divided the colon and rectal tumor patients in this study. Moreover, there was no significant difference in tumor localizations. However, increasing the number of cases due to the distinction between the colon and the rectal tumors may have different consequences.

Although NLR test has advantages such as being simple and affordable and the ability to study among routine tests, it may be affected by several external factors. Non-randomization and the reduced number of patients were disadvantages of this study.

If the study's design had been prospective, the standardization of preoperative whole blood count and evaluation of specimens by the same pathologists might have affected the results.
Neutrophil-lymphocyte ratio may have a sufficient prognostic value alone when evaluated together with the literature. However, it still has limited clinical use due to many non-carcinogenic and carcinogenic factors affecting neutrophil and lymphocyte counts in daily use.

We think that this matter will be clarified with more detailed meta-analyses in large-scale studies.

\section{CONCLUSION}

The study showed that high NLR has an adverse effect on the OS in patients who have undergone a curative surgery. However, we could not establish any association between NLR and the factors such lymphovascular invasion, perineural invasion, and tumor size, except hemoglobin and serum albumin levels.

Ethics Committee Approval: Ethics committee approval was received for this study from the ethics committee of Gaziantep University (20.01.2014/48).

Informed Consent: Informed consent was not received due to the retrospective nature of the study.

Peer-review: Externally peer-reviewed.

Author Contributions: Concept - A.B., E.B.; Design - E.B., Z.B., K.A.; Supervision - A.B., E.B., I.B.; Materials - A.B., E.B., I.B., Z.B.; Data Collection and/or Processing - K.A., A.A., L.Y., M.E.; Analysis and/or Interpretation - E.B., K.A.; Literature Search - E.B., K.A., Z.B.; Writing Manuscript - E.B., A.A., L.Y.; Critical Reviews - A.B., İ.B.

Conflict of Interest: No conflict of interest was declared by the authors. 
Financial Disclosure: The authors declared that this study has received no financial support.

\section{REFERENCES}

1. The National Cancer Institute. Cancer of the colon and the rectum. Accessed November 16, 2014. Available from: URL: http:// seer.cancer.gov/statfacts/html/colorect.html.

2. Ropponen KM, Eskelinen MJ, Lipponen PK, Alhava E, Kosma VM. Prognostic value of tumor-infiltrating lymphocytes (TILs) in colorectal cancer. J Pathol 1997; 182: 318-324. [CrossRef]

3. Nielsen HJ, Hansen U, Christensen IJ, Reimert CM, Brünner N, Moesgaard F. Independent prognostic value of eosinophil and mast cell infiltration in colorectal cancer tissue. J Pathol 1999; 189: 487-495. [CrossRef]

4. Galon J, Costes A, Sanchez-Cabo F, Kirilovsky A, Mlecnik B, Lagorce-Pages $C$, et al. Type, density, and location of immune cells within human colorectal tumors predict clinical outcome. Science 2006; 313: 1960-1964. [CrossRef]

5. McMillan DC, Crozier JE, Canna K, Angerson WJ, McArdle CS. Evaluation of an inflammation-based prognostic score (GPS) in patients undergoing resection for colon and rectal cancer. Int J Colorectal Dis 2007; 22: 881-886. [CrossRef]

6. Ishizuka M, Nagata H, Takagi K, Horie T, Kubota K. Inflammationbased prognostic score is a novel predictor of postoperative outcome in patients with colorectal cancer. Ann Surg 2007; 246: 1047-1051. [CrossRef]

7. Walsh SR, Cook EJ, Goulder F, Justin TA, Keeling NJ. Neutrophillymphocyte ratio as a prognostic factor in colorectal cancer. J Surg Oncol 2005; 91: 181-184. [CrossRef]

8. Ding PR, An X, Zhang RX, Fang YJ, Li LR, Chen G, et al. Elevated preoperative neutrophil to lymphocyte ratio predicts risk of recurrence following curative resection for stage IIA colon cancer. Int J Colorectal Dis 2010; 25: 1427-1433. [CrossRef]

9. Epitelial tumours of the large intestine (part 6). In: Day DW, Jass JR, Price AB, Shepherd NA, Sloan JM, Talbot IC, et al. editors. Morson and Dawson's Gastrointestinal Pathology. 4th ed. Oxford: Blackwell Science; 2003. 38; p:551

10. Gordon PH. Malignant neoplasms of the Colon. In: Gordon Ph, Nivatvongs S. Neoplasms of the colon, rectum, and anus. 2nd ed. New York: Informa Healthcare USA, 2007. p:163-164. [CrossRef]
11. Martin EW Jr, Joyce S, Lucas, J, Clausen K, Cooperman M. Colorectal carcinoma in patients less than 40 years of age: pathology and prognosis. Dis Colon Rectum 1981; 24: 25-28. [CrossRef]

12. Krasna MJ, Flancbaum L, Cody RP, Shneibaum S, Ben Ari G. Vascular and neural invasion in colorectal carcinoma. Incidence and prognostic significance. Cancer 1998; 61: 1018-1023. [CrossRef]

13. Horn A, Dahl O, Morild I. Venous and neural invasion as predictors of recurrence in rectal adenocarcinoma. Dis Colon Rectum 1991; 34: 798-804. [CrossRef]

14. Jankova L, Dent OF, Chan C, Chapuis P, Clarke SJ. Preoperative neutrophil/lymphocyte ratio predicts overall survival but does not predict recurrence or cancer-specific survival after curative resection of node-positive colorectal cancer. BMC Cancer 2013; 13: 442. [CrossRef]

15. Malietzis G, Giacometti M, Askari A, Nachiappan S, Kennedy RH, Faiz OD, et al. A preoperative neutrophil to lymphocyte ratio of 3 predicts disease-free survival after curative elective colorectal cancer surgery. Ann Surg 2014; 260: 287-292. [CrossRef]

16. Chiang SF, Hung HY, Tang R, Changchien CR, Chen JS, You YT, et al. Can neutrophil-to-lymphocyte ratio predict the survival of colorectal cancer patients who have received curative surgery electively? Int J Colorectal Dis 2012; 27: 1347-1357. [CrossRef]

17. Roxburgh CS, Salmond JM, Horgan PG, Oien KA, Mcmillan DC. Comparison of the prognostic value of inflammation-based pathologic and biochemical criteria in patients undergoing potentially curative resection for colorectal cancer. Ann Surg 2009; 249: 788-793. [CrossRef]

18. Klintrup K, Mäkinen JM, Kauppila S, Väre PO, Melkko J, Tuominen $\mathrm{H}$, et al. Inflammation and prognosis in colorectal cancer. Eur J Cancer 2005; 41: 2645-2654. [CrossRef]

19. Ozdemir Y, Akin ML, Sucullu I, Balta AZ, Yucel E. Pretreatment neutrophil lymphocyte ratio as a prognostic aid in colorectal cancer. Asian Pac J Cancer Prev 2014; 15: 2647-2650. [CrossRef]

20. Mlecnik B, Tosolini M, Kirilovsky A, Berger A, Bindea G, Meatchi T, et al. Histopathologic-based prognostic factors of colorectal cancers are associated with the state of the local immune reaction. J Clin Oncol 2011; 29: 610-618. [CrossRef] 